advised me to furnish a psychiatric report to the Managers, but promised to follow up the matter further if I sent them a copy of this booklet.

I have since discussed this matter with my consultant colleagues, and all of them agree that there seems to be uncertainty, either in the Act, or in its interpretation.

It seems a discrepancy that a patient admitted to hospital by a court following evidence by two doctors, one of whom is "approved", cannot appeal to the MHRT within the first period of detention but yet can do so to the Managers of the hospital. The implications of this are that a panel of three Managers (who are usually neither medically nor psychiatrically trained, nor legally qualified), could discharge a patient detained under Section 37 within the first period of detention even though the MHRT cannot do so.

I would be most interested in hearing from colleagues who have had similar experiences, or who have any views on this matter. Of course, what would be most interesting to hear about would be if anyone has actually had a patient on Section 37 discharged by the Managers of the hospital within the first period of detention.

North Wales Hospital

Pradeep Singhal

Denbigh, Clwyd

\section{Section 2 of the Mental Health Act 1983}

\section{DEAR SIRS}

I would be grateful for space in the Bulletin, to share with the readership certain problems noted with Managers' Meetings and Mental Health Review Tribunals. These have to do especially with patients admitted under Section 2 of the Mental Health Act. As things stand, such patients are entitled to appeal against their detention during their first 14 days in hospital. Many go on to appeal immediately, and, as per procedure, such appeals must be heard within five days or so. The result is that the RMO finds himself preparing a report for the hearing, before he has the opportunity to make meaningful assessment.

That patients liable to be detained under the Act are free to appeal to both the Hospital Managers and the Mental Health Review Tribunal, only makes matters worsebecause that situation calls upon the RMO to prepare two reports, and attend two hearings, whilst the assessment for which the patient was admitted is yet to be completed.

I would like to suggest that the Act be amended to read that patients detained under the provisions of Section 2 may appeal against their detention only if they are still detained after 14 days. This would give the RMO and his/her team the opportunity to carry out a clear-headed assessment of the patient, without rushing through matters in order to have a cogent viewpoint to offer the Hospital Managers or the Mental Health Review Tribunal. I would also suggest that the patients are permitted only one appeal during the period of their detention; thus, they may appeal to either the Managers or the MHRT, and not to both.

The question of course arises, what is the real status of the decisions of the Hospital Managers? If their decisions carry the same weight as those of the Tribunal, what is the point in appealing to two 'Courts' of equal authority to discharge or refuse discharge? If the decisions of the Managers are not of equal authority to those of the MHRT, what then is the purpose of the Managers' Meetings?

\section{Claybury Hospital}

I. O. AZUONYE Woodford Green, Essex

\section{Japanese psychiatry}

\section{DeAR Sirs}

I feel it is my responsibility to comment on Dr Bourne's discussion of the current state of Japanese psychiatry (Bulletin. August 1987, 11, 286) since I am the first and probably still the only Japanese member of the College.

Dr Bourne was right in stating that much remained to be done in Japanese psychiatry and that the present Mental Health Act should be reformed urgently. Unsatisfactory conditions of psychiatric in-patients in Japan have been reported from time to time by journalists and psychiatric professionals. The present movement of the reformation was precipitated by one of those reports, a scandal in a mental hospital. I am not qualified to discuss the scandal itself. The UN and ICJ (International Commission of Jurists), however, became aware of it and the condition of Japanese psychiatry and apparently urged the Japanese government to take action. A new bill now waits to be discussed in the current Diet extraordinary session, though it may not be without much debate before it is finalised and passed.

Here, I should like to emphasise the importance of psychiatric education both graduate and postgraduate, medical and paramedical. Dr Bourne quoted Mr Totsuka as saying that there is virtually no psychiatry in Japanese medical education and doctors wishing to specialise have to get their training outside the country.

Every medical school teaches psychiatry and has a psychiatric department. What Mr Totsuka meant to point out, however, is the inadequacy of the content of the postgraduate education. Although most university departments, mental hospitals and clinics seem enthusiastic in educating trainees, there exists no formal specialist qualification or examination. Nor is there any standard of curriculum of postgraduate education. It seems that only individual interest and a feeling of responsibility and devotion drives young physicians to acquire the necessary skills and knowledge. Those who are less interested in further education may be less likely to be capable of judging whether their skills and knowledge are adequate.

Improved as the new law may be, its purpose should and can only be embodied by those with specialist qualifcations. Otherwise the new law may remain only as a source of red tape.

National Institute of Mental Health

T. KITAMURA 